\title{
A Case of Severe Anemia in an Aids Patient
}

Amy K. Slenker, MD, and Rahul Anand, MD

\section{Case Presentation}

A 49 year-old African-American male presented to Thomas Jefferson University Hospital in April of 2008 complaining of generalized weakness and lightheadedness for 4 months. The patient had a medical history of HIV/AIDS diagnosed in 2002 with a CD4 count of 0 cells $/ \mathrm{mm}^{3}$ in 2005 and a history of noncompliance with highly active retroviral therapy (HAART). In December of 2007 the patient was diagnosed with cryptococcal meningitis and had a concomitant anemia with a hemoglobin of $5.3 \mathrm{~g} / \mathrm{dL}$. At that time laboratory studies for parvovirus B19 (PB19) showed an IgG of 0.79 units and an IgM of 0.63 units ( a value less than 0.89 is considered negative). PB19 DNA by PCR or direct DNA hybridization was not checked at that time. A bone marrow biopsy was performed in January of 2008 to determine the etiology of this severe hypoproliferative anemia, revealing hypercellular marrow containing maturing trilineage hematopoiesis with occasional non-caseating granulomas with fungal elements. It was felt at this time that the anemia was secondary to cryptococcal invasion of the bone marrow. The patient was treated for cryptococcal meningitis with fluorocytosine and liposomal amphotericin B for 2 weeks, followed by oral fluconazole indefinitely, and was discharged from the hospital.

When the patient presented in April of 2008, he was admitted through the emergency department (ED) for a work-up of symptomatic anemia. The patient was complaining of lightheadedness, generalized weakness, watery diarrhea, dry cough, and shortness of breath. The patient denied fever, night sweats, headache, blurry vision, joint pains, or rash. The patient denied bloody or tarry stools, bleeding gums, easy bruising, or trauma. On exam, the patient was afebrile and appeared disheveled and cachectic with marked pallor. The patient had multiple small cervical lymph nodes, no evidence of jugular venous distension, and was clear to auscultation on lung exam. He had a regular cardiac rhythm with no murmurs, a benign abdominal exam with no hepatosplenomegaly, and no rashes, petechiae, or peripheral edema.

The patient's hemoglobin in the emergency room was $2.9 \mathrm{~g} / \mathrm{dL}$, with a previous level of $13.1 \mathrm{~g} / \mathrm{dL}$ one year prior to this admission. The patient's WBC count was $8.2 \mathrm{~g} / \mathrm{dL}$, with a differential of $24 \%$ neutrophils, $9 \%$ bands, $23 \%$ lymphocytes, $28 \%$ monocytes, and $3 \%$ eosinophils, $3 \%$ metamyelocytes, and $9 \%$ myelocytes. Laboratory values were as follows: mean corpuscular volume was $87 \mathrm{fL}$ (80-99 fL), lactate dehydrogenase $285 \mathrm{IU} / \mathrm{L}$ (100-200 IU/L), haptoglobin $331 \mathrm{mg} / \mathrm{dL}$ (16-200 mg/dL), urea-nitrogen $15 \mathrm{mg} / \mathrm{dL}$, creatinine $1.7 \mathrm{mg} / \mathrm{dL}$, aspartate aminotransferase 16 $\mathrm{IU} / \mathrm{L}$, alanine aminotransferase $11 \mathrm{IU} / \mathrm{L}$, alkaline phosphatase $103 \mathrm{IU} / \mathrm{L}$, albumin $3.6 \mathrm{~g} / \mathrm{dL}$, total bilirubin $0.3 \mathrm{mg} / \mathrm{dL}$, and direct bilirubin $0.0 \mathrm{mg} / \mathrm{dL}$. CMV quantitative PCR was $<100$ copies/mL ( $<100$ copies $/ \mathrm{ml}$ is negative). AFB stain from feces and blood cultures were negative. Stool studies were negative for Entamoeba histolytica, Giardia lamblia, Cryptosporidium species, Clostridium difficile and Shigella, Salmonella, and Campylobacter species. The patient's absolute reticulocyte count was 3 cells $/ \mathrm{mm}^{3}$ ( $20-76$ cells $\left./ \mathrm{mm}^{3}\right)$, HIV viral load was 483,000 copies/mL and CD4 count was 7 cells $/ \mathrm{mm}^{3}$. PB19 DNA by PCR was positive, and there was a positive antibody response with an IgG of 1.56 index units and $\operatorname{IgM}$ of 4.84 index units.

The patient received four units of packed red blood cells in the ED and was subsequently started on intravenous immune globulin (IVIG), to which he responded with a sustained increase in his hemoglobin and no further requirements of packed red blood cell transfusions. The patient's acute renal failure was felt to be secondary to pre-renal causes and improved to a baseline value with fluid resuscitation. The patient was also started on HAART with Atazanavir boosted with Ritonavir, and Tenofovir-Emtricitabine. The patient's hemoglobin on discharge was $9.3 \mathrm{~g} / \mathrm{dL}$ with an absolute reticulocyte count of 198 cells $/ \mathrm{mm}^{3}$. On follow up, he continues to be non-compliant with his HAART medications, but his repeat complete blood count three months later in August 2008 revealed a hemoglobin of $9.0 \mathrm{~g} / \mathrm{dL}$. Furthermore, the patient has not required a blood transfusion since he completed IVIG treatment.

\section{Discussion}

Anemia is a common finding in HIV-infected patients. Several causes of anemia have been described including medications (e.g., antiretrovirals or trimethoprim-sulfamethoxazole), neoplasms, opportunistic infections, and the immunological effects of HIV itself. Although uncommon, PB19-related pure red cell aplasia (PRCA) is an important diagnosis to consider in this setting because it is a treatable cause of anemia. ${ }^{2,5}$ Human $\mathrm{PB} 19$ infection is found worldwide in persons of all ages, with the majority of adults having been exposed to the virus by age 50 . The virus can be asymptomatic or can present in a variety of ways including as erythema infectiosum, arthropathy, a papular rash, pure red cell aplasia, hydrops fetalis in the neonate, and other cardiac, rheumatologic, and neurological manifestations. ${ }^{2}$ ${ }^{12}$ PB19 usually causes a benign, self-limited illness, but the virus can present as a severe anemia in the immunocompromised host. $^{1,5}$

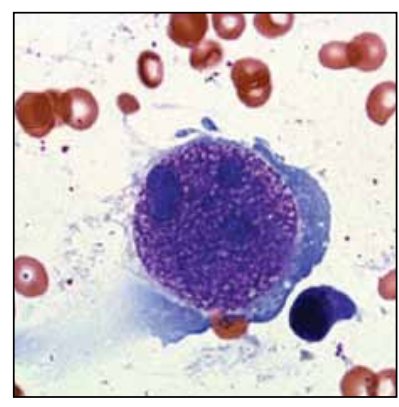

Figure 1. Characteristic giant proerythroblasts in the bone marrow are pathognomonic for parvovirus B19 infection. The diagnosis may be missed if the biopsy is done within a few days of a blood transfusion. 
HIV-infected patients are particularly susceptible to infection with PB19 and may be unable to produce an adequate antibody response to the virus. This can result in a severe PRCA and a prolonged anemia as the PB19 interrupts the production of red blood cells in the bone marrow., ${ }^{5,6}$ These patients have been shown to respond to a PB19 triggered PRCA with both IVIG therapy as well as with highly active antiretroviral therapy. ${ }^{7,10} \mathrm{In}$ this case report, our patient presented with a profound anemia caused by parvovirus B19 and responded well to treatment with IVIG. The patient was also started on HAART, but was again non-compliant with his medications.

A diagnosis of B19-PRCA should be considered in an afebrile, HIV-infected patient with a normocytic anemia of relatively recent onset, a virtual absence of blood reticulocytes, and a normal renal function. Most reported cases are with a CD4 count less than 100 cells $/ \mathrm{mm} .{ }^{7,12}$ The symptomatology is nonspecific, and fever, skin rash, and arthropathy are characteristically absent. Diagnosis of PB19-induced PRCA in an HIV-infected patient is established when the following criteria are met: a bone marrow aspirate consistent with PB19, a positive serum PB19 DNA by PCR or direct DNA hybridization, and no alternate explanation for the red cell aplasia.?

It is important to note that the diagnosis may be missed in immunocompromised patients because these patients may not be able to formulate antibodies to the virus. Thereby, only checking IgM and IgG antibodies to PB19 is not sufficient to exclude the diagnosis, and either DNA by PCR or direct DNA hybridization must be ordered. ${ }^{4}$ There are no clinical guidelines about the treatment of HIV patients with PB19 infection; however, multiple small studies have shown success with IVIG treatment with good initial response. In patients with a CD4 count less than 80 cells $/ \mathrm{mm}^{3}$, there is an unfortunately high relapse rate. ${ }^{8,9}$ For this reason, HAART has been described as a treatment strategy to consider for PB19-induced PRCA, with some success reported in small case studies. ${ }^{3,10}$ With substantive data lacking at this time, adequate treatment for PB19 in HIV infected patients should be determined in conjunction with an infectious diseases specialist and should include close follow-up.

\section{References}

1. Abkowitz, JL, Brown, KE, Wood, RW, et. al. Clinical relevance of parvovirus B19 as a cause of anemia in patients with human immunodeficiency virus infection. Journal of Infectious Diseases. 1997; 176(1):269-73.

2. Broliden, $\mathrm{K}$, Tolfvenstam, T, Norbeck, O. Clinical aspects of parvovirus B19 infection. Journal of Internal Medicine. 2006; 260(4):285-04.

3. Chen, MY, Hung, CC, Fang, CT, et al. Reconstituted immunity against persistent parvovirus B19 infection in a patient with acquired immunodeficiency syndrome after highly active antiretroviral therapy. Clinical Infectious Diseases. 2001; 32(9):1361-5.

4. Chernak, E, Dubin, G, Henry, D, et. al. Infection due to parvovirus B19 in patients infected with human immunodeficiency virus. Clinical Infectious Diseases. 1995; 20(1):170-3.

5. Florea, AV, Ionescu, DN, Melhem, MF, Parvovirus B19 infection in the immunocompromised host. Archives of Pathology \& Laboratory Medicine. 2007; 131(5):799-04.

6. Frickhofen, N, Abkowitz, JL, Safford, M, et. al. Persistent B19 parvovirus infection in patients infected with human immunodeficiency virus type 1 (HIV1): a treatable cause of anemia in AIDS. Annals of Internal Medicine. 1990; 113(12):926-33.

7. Koduri, PR. Parvovirus B19-related anemia in HIV-infected patients. AIDS Patient Care \& STDs. 2000; 14(1):7-11.

8. Koduri, PR, Kumapley, R, Valladares, J, et. al. Chronic pure red cell aplasia caused by parvovirus B19 in AIDS: use of intravenous immunoglobulin--a report of eight patients. American Journal of Hematology. 1999; 61(1):16-20.

9. Kurzman, G, Frickenhofen, N, Kimball, J, et. al. Pure red cell aplasia of 10 years' duration due to persistent parvovirus B19 infection and its cure with immunoglobulin therapy. New England Journal of Medicine. 1989; 321:519-23.

10. Morelli, P, Bestetti, G, Longhi, E, et. al. Persistent parvovirus B19-induced anemia in an HIV-infected patient under HAART. European Journal of Clinical Microbiology \& Infectious Diseases. 2007; 26(11):833-7.

11. Mylonakis, E, Dickinson, BP, Mileno, MD, et. al. Persistent parvovirus B19 related anemia of seven years' duration in an HIV-infected patient: complete remission associated with highly active antiretroviral therapy. American Journal of Hematology. 1999; 60(2):164-6.

12. Servey, JT, Reamy, BV, Hodge, J. Clinical presentations of parvovirus B19 infection. American Family Physician. 2007; 75(3):373-6.

13. van Elsacker-Neile, AM, Kroon, FP, van der Ende, ME, et. al. Prevalence of parvovirus B19 infection in patients infected with human immunodeficiency virus. Clinical Infectious Diseases. 1996; 23(6):1255-60.

14. Vernazza, PL, Pfister, LA, Siegl, G, Cassinotti, P. High seroprevalence of parvovirus B19 among patients infected with human immunodeficiency virus. Clinical Infectious Diseases. 1996; 22(1):198-9.

15. Ware, AJ, Moore, T. Resolution of chronic parvovirus B19-induced anemia, by use of highly active antiretroviral therapy, in a patient with acquired immunodeficiency syndrome. Clinical Infectious Diseases. 2001; 32(7):E122-3.

16. Young, NS, Brown, KE. Parvovirus B19. New England Journal of Medicine. 2004 350(6):586-97. 